\title{
A comparison of three treatment strategies in recent onset non-systemic Juvenile Idiopathic Arthritis: initial 3-months results of the BeSt for Kids-study
}

P. C. E. Hissink Muller ${ }^{1,6^{*}}$, D. M. C. Brinkman ${ }^{1,2}$, D. Schonenberg ${ }^{3}$, Y. Koopman-Keemink ${ }^{4}$, I. C. J. Brederije ${ }^{1}$, W. P. Bekkering ${ }^{1}$, T. W. Kuijpers ${ }^{3}$, M. A. J. van Rossum ${ }^{5}$, L. W. A. van Suijlekom-Smit ${ }^{6}$, J. M. van den Berg ${ }^{3}$, C. F. Allaart ${ }^{7}$ and R. ten Cate ${ }^{1}$

\begin{abstract}
Background: Combination therapy with prednisone or etanercept may induce earlier and/or more improvement in disease activity in Disease Modifying Anti Rheumatic Drug (DMARD) naïve non-systemic Juvenile Idiopathic Arthritis (JIA) patients. Here we present three months clinical outcome of initial treatments of the BeSt-for-Kids study.

Methods: Included patients were randomized to either: 1. initial DMARD-monotherapy (sulfasalazine (SSZ) or methotrexate (MTX)), 2. Initial MTX / prednisolone-bridging, 3. Initial combination MTX/etanercept. Percentage inactive disease, adjusted (a) ACR Pedi30, 50 and 70 and JADAS after 6 and 12 weeks of treatment (intention to treat analysis) and side effects are reported.
\end{abstract}

Results: 94 patients (67\% girls, 32 (arm 1), 32 (arm 2) and 30 (arm 3) with median (InterQuartileRange) age of 9.1 (4.7-12.9) years were included. 38\% were ANA positive, 10 had oligo-articular disease, 68 polyarticular JIA and 16 psoriatic arthritis. Baseline median (IQR) ACRpedi-scores: VAS physician 49 (40-58) mm, VAS patient 54 (37-70) mm, ESR 6.5 (2-14.8)mm/hr, active joint count 8 (5-12), limited joint count 3 (1-5), CHAQ score 0.88 (0.63-1.5). In arm 1, 17 started with MTX, 15 with SSZ.

After 3 months, aACR Pedi 50 was reached by 10/32 (31\%), 12/32(38\%) and 16/30 (53\%) ( $p=0.19)$ and aACR Pedi 70 was reached by $8 / 32(25 \%), 6 / 32(19 \%)$ and $14 / 30(47 \%)$ in arms $1-3(p=0.04)$. Toxicity was similar. Few serious adverse events were reported.

Conclusion: After 3 months of treatment in a randomized trial, patients with recent-onset JIA achieved significantly more clinical improvement (aACRPedi70) on initial combination therapy with MTX / etanercept than on initial MTX or SSZ monotherapy.

Trial registration: NTR1574. Registered 3 December 2008.

Keywords: Juvenile idiopathic arthritis, Treat to target, Window of opportunity, Treatment strategy study, Biologicals, Inactive disease

\footnotetext{
* Correspondence: p.hissinkmuller@lumc.nl

${ }^{1}$ Department of Pediatrics/Pediatric Rheumatology, Leiden University Medical

Center, Leiden, The Netherlands

${ }^{6}$ Department of Pediatrics/Pediatric Rheumatology, Erasmus MC Sophia

Children's Hospital, Rotterdam, The Netherlands

Full list of author information is available at the end of the article
}

\section{Ciomed Central}

(c) The Author(s). 2017 Open Access This article is distributed under the terms of the Creative Commons Attribution 4.0 International License (http://creativecommons.org/licenses/by/4.0/), which permits unrestricted use, distribution, and reproduction in any medium, provided you give appropriate credit to the original author(s) and the source, provide a link to the Creative Commons license, and indicate if changes were made. The Creative Commons Public Domain Dedication waiver (http://creativecommons.org/publicdomain/zero/1.0/) applies to the data made available in this article, unless otherwise stated. 


\section{Introduction}

Juvenile Idiopathic Arthritis (JIA) is the most common auto-immune disease in children [1] except for systemic JIA which is nowadays viewed as an autoinflammatory disease [2]. Many children suffer from chronic functional disability and damage due to prolonged inflammation [3]. The ILAR criteria divide the heterogeneous disease in 7 categories [4]. Prognosis is difficult to predict and even oligoarticular disease can have a debilitating course [5]. Nowadays an expanding repertoire of disease modifying antirheumatic drugs (DMARD) including biologicals is available for treatment [6]. Evidence-based information is available on the efficacy of individual products [7-15] but knowledge on therapeutic strategies in children is still scarce [16, 17]. As shown in the BeSt study in rheumatoid arthritis patients[18], it is likely and was illustrated previously that also in JIA a window-ofopportunity exists where the disease is most responsive to treatment and susceptible for permanent suppression [11, 16, 17, 19]. Additionally we know that an early response to therapy is related to a better outcome [20, 21].

In the current study we investigate which of 3 treatment strategies is most effective, fast-acting and safe in a randomized clinical trial comparing three initial therapies: arm 1 initial monotherapy with MTX or SSZ; arm 2 initial combination therapy with MTX and prednisolone and arm 3 initial combination therapy with etancercept and MTX. We hypothesized that compared to initial monotherapy (arm 1) with sulphasalazine or methotrexate or initial combination therapy with MTX/prednisone (arm 2) early treatment with etanercept and methotrexate (arm 3) would lead to significantly more and earlier clinical inactive disease.

\section{Methods \\ Patients}

Patients diagnosed as DMARD-naive JIA, either rheumatoid factor negative polyarticular, oligoarticular JIA, or juvenile psoriatic arthritis, in need of systemic DMARD therapy according to treating physician, with less than 18 months of complaints, aged between 216, were eligible at 5 participating sites in the Netherlands. Patients suffering from rheumatoid factor-positive JIA are preferably treated with combination therapy from the start and were excluded [17] as well as systemic JIA and Enthesitis Related JIA since they comprise of JIA patients with different clinical features potentially increasing heterogeneity. Patients with JIA related uveitis were excluded due to possible exposure to etanercept which is known to be less effective in uveitis treatment [22-26].

\section{Study design}

Data are collected through the BeSt for Kids study, an investigator-initiated multicentre randomised single blinded clinical trial which will have 2 years follow-up in three treatment arms in a treat-to-target setting. The study was approved by the Medical Ethical Committee of the Leiden University Medical Center and local Ethical Committees prior to start at each study site. Written Informed consent was obtained from patients above 12 years of age and parents of all participating patients. Patients were enrolled and randomly assigned to one of three treatment arms by variable block randomization, stratified per center, as oligo or polyarticular disease.

\section{Initial treatments}

Patients assigned to arm 1 started with Sulphasalazine $50 \mathrm{mg} / \mathrm{kg}$ up to $2000 \mathrm{mg} /$ day or MTX $10 \mathrm{mg} / \mathrm{m} 2 /$ wk orally or subcutaneous (sc)(max $25 \mathrm{mg} / \mathrm{wk}$ ).

Patients assigned to arm 2 started with MTX $10 \mathrm{mg} / \mathrm{m} 2 / \mathrm{wk}$ orally or sc ( $\max 25 \mathrm{mg} / \mathrm{wk})$ in combination with prednisolone orally $0,5 \mathrm{mg} / \mathrm{kg}$ for four weeks, tapering by 1 week $0,25 \mathrm{mg} / \mathrm{kg}$ and 1 week $0,125 \mathrm{mg} / \mathrm{kg}$, then stop.

Patients assigned to arm 3 started with a combination of etanercept $0,8 \mathrm{mg} / \mathrm{kg} / \mathrm{wk}$ sc and MTX $10 \mathrm{mg} / \mathrm{m} 2 / \mathrm{wk}$ orally or sc $(\max 25 \mathrm{mg})$.

Prior to etanercept treatment, all children were screened for tuberculosis by a purified protein derivative skin test and a chest radiograph. All tested negative. Concomitant treatment with non-steroidal antiinflammatory drugs (NSAIDs) and intra-articular glucocorticoid injections were permitted without a maximum and registered per strategy. Other parenteral glucocorticoids were not allowed. The use of DMARD or oral glucocorticoids was only permitted as dictated by the treatment protocol. All protocol deviations were recorded. All patients received folic acid during MTX treatment.

\section{Assessment of disease activity: definition of improvement and inactive disease}

The core set criteria [27] were scored at 6 weeks and 3 months by a research nurse, physical therapist or pediatric rheumatologist who remained blinded to the allocated treatment group during study period. Since the protocol was written in 2008 inactive disease on medication was defined based on the modified Wallace 2004 definition [28] instead of the current definition [29]. Based on previous results [30] we stated that a doctor's overall assessment score below $10 \mathrm{~mm}$ (instead of $0 \mathrm{~mm}$ ) on the VAS indicated no disease activity provided that all other parameters as defined 
[28] indicated inactive disease. We defined ESR values under $16 \mathrm{~mm} / \mathrm{h}$ as normal.

Definition of improvement was based on ACRPedi30/50/ $70 \%$ [27]. Changes in outcomes that remained within normal limits $(E S R \leq 16 \mathrm{~mm} / \mathrm{h}$ and VAS physician $<10 \mathrm{~mm}$ ) were not taken into account in ACRPedi calculations and were corrected for, resulting in adjusted (aACRPedi30/50/ 70\%) scores.

Juvenile Arthritis Disease Activity Score (JADAS)-10 score were calculated as described previously [31]. Delta JADAS10 was defined as the difference between JADAS10 score at subsequent visits with baseline score.

\section{Toxicity}

At each visit (baseline, 6 weeks, 12 weeks), laboratory tests were performed as clinically indicated: complete blood count, liver and kidney function. The treating physician recorded all adverse events (AEs), serious adverse events (SAEs), and if necessary, made treatment adjustments in accordance to the protocol. SAEs were defined as any adverse reaction resulting in any of the following outcomes: a life threatening condition or death, a significant or permanent disability, a malignancy, and (prolonged) hospitalization.

\section{Sample size calculations}

Expected percentages of time to inactive disease were extrapolated from available literature in 2008 [9, 11, 13] and based on estimation. For the comparison of arm 1 versus arm 3, with power $>90 \%$ a difference of $10 \%$ in arm 1 versus $60 \%$ in arm 3 can be detected with two groups of 30 patients assuming a hazard ratio of 8.70 , a drop-out rate $20 \%$, a percentage that switched groups $20 \%$, an alpha 0.05 , by two-sided log rank test. Based on analogous calculations (PASS2008) two groups of 45 and 54 patients were needed to detect differences between arm 2 versus arm 3 and between arm 1 versus arm 2 . Initially 60 patients per arm was aimed for. Due to slow inclusion rate, the study protocol was amended in 2012 to include 3 groups of 30 patients, leaving enough power to compare arm 1 versus arm 3.

\section{Statistical methods}

Missing data in core set variables were scarce $(<1 \%)$. All available data were included for intention-to-treat analysis. Last observation carried forward was used to deal with few missing values $(n=5)$. Student's $t$-test was used to compare continuous normally distributed variables between groups. Non-parametric Mann Whitney U tests were used otherwise. For dichotomous variables, Pearson's chi-square test was used. A two-tailed probability value of $\mathrm{P}<0.05$ was considered statistically significant. P-values were not adjusted for multiple statistical tests.

The Trial was registered in the Dutch Trial Register number 1574.

\section{Results}

\section{Baseline characteristics}

Baseline demographics and disease characteristics of the three groups showed no statistically significant differences and are summarized in Table 1.

\section{Outcome}

Figure 1 shows the flow diagram of the study. 94 patients with early JIA, with a median duration between diagnosis and inclusion of 6 weeks (IQR 3-14) and a median duration of symptoms of 7.5 months (IQR 5-12,5), were randomized to one of three treatment groups: 32 patients assigned to monotherapy (arm 1), 32 patients assigned to combination with methotrexate and prednisone-bridging ( $\mathrm{arm} 2)$ and 30 patients were assigned to combination of etanercept and methotrexate (arm 3).

\section{Adjusted ACRPedi30/50/70 and early inactive disease}

Results are summarized in Table 2. From the patients in inactive disease according to our definition: $11 / 21(52 \%)$ had a VAS physician of $0 \mathrm{~mm}$, while $10 / 21(48 \%)$ had a VAS that was scored $>0 \mathrm{~mm}$, the average was $3.8 \mathrm{~mm}$.

\section{Medication changes and protocol violations}

Medication changes and protocol violations are summarized in Table 3. In arm 1 and arm 2 more medication changes occurred compared to arm 3 in the first three months of therapy due to adverse events $(n=5)$. Use of prednisone outside of protocol occurred 3 times in arm 1 . Of the 15 patients who started on SSZ, 3 switched to MTX after 6 weeks due to nausea, malaise, headache.

\section{Adverse events}

A summary of toxicity is given in Table 4 . A total of $28 \%$ (26/94) of all patients experienced $\geq$ one AEs: 7/32(22\%), 9/32 (28\%) and 10/30(33\%). Gastro-intestinal symptoms were most frequently reported and were observed $7 / 32$ (22\%), 14/32 (44\%) and 9/30(28\%) in arm 1, 2 and 3. Second mostly reported were mild infectious complications (8/32 (25\%)in arm 1, 6/32 (19\%) in arm 2 and 13/30 (43\%) in arm 3) with 8 upper respiratory tract infections documented in arm 3. Hospital admissions accounted for 3 SAEs in the first three months. One SAE due to viral pneumonia with mild oxygen demand ( on SSZ, arm 1), one patient (on MTX, arm 1) suffered from prolonged vomiting which resolved after admission and stopping of MTX. One patient (on MTX, arm 2) had fever of 
Table 1 Baseline demographics and disease characteristics

\begin{tabular}{llll}
\hline & $\begin{array}{l}\text { Arm 1 } \\
\text { MTX or SSZ monotherapy } \\
(n=32)\end{array}$ & $\begin{array}{l}\text { Arm 2 } \\
\text { Combo MTX+6 wks prednisone } \\
(n=32)\end{array}$ & $\begin{array}{l}\text { Arm 3 } \\
\text { Combo MTX+ etanercept } \\
(n=30)\end{array}$ \\
\hline Age (years) & $\begin{array}{l}(8.8(4.8-12.7) \\
\text { Symptom duration* (month) }\end{array}$ & $10.2(6.6-13.9)$ & $8.6(4.2-12.4)$ \\
ANA positive (\%) & $7.8(5.3-11.6)$ & $5.9(4.4-13.3)$ & $8.5(5.0-13.1)$ \\
Female (\%) & $15(47)$ & $11(34)$ & $20(30)$ \\
JIA category: & $24(75)$ & $19(59)$ & $20(67)$ \\
Oligo (persistent) & & & $2(2)$ \\
Poly articular & $5(3)$ & $3(1)$ & 24 \\
Psoriatic (poly) & 22 & 22 & 4 \\
VAS physician (mm) & 5 & 7 & $51(37-61)$ \\
VAS patient/parent (mm) & $48(40-55)$ & $50(39-58)$ & $58(39-71)$ \\
CHAQ (0-3) & $48(31-58)$ & $59(35-74)$ & $0.88(0.75-1.53)$ \\
No. active joints & $0.88(0.28-1.50)$ & $0.94(0.63-1.69)$ & $8.5(5.8-13.0)$ \\
No. limited joints & $7.5(5.0-12.5)$ & $7.5(6.0-11.8)$ & $3(1.8-5.0)$ \\
ESR (mm/hour) & $2(0-4.5)$ & $2(1.0-3.8)$ & $9.0(4-25)$ \\
JADAS-10 (0-40) & $6.5(2-11)$ & $6.0(2-24)$ & $19.1(13.8-23.2)$ \\
\hline
\end{tabular}

All results in medians (InterQuartile Range) unless stated otherwise;*time from first presenting symptoms to inclusion in the study

unknown origin while on MTX and was observed shortly without additional therapy.

\section{Discussion}

In the BeSt for Kids study, early clinical improvement in patients with early JIA was the aim of the three initial therapies: initial monotherapy with MTX or SSZ, MTX with initial bridging with prednisone, and MTX with etanercept. We found comparable outcomes in all three arms, with the exception that initial combination therapy with etanercept /MTX resulted in a significantly higher percentage of children that had reached aACRPedi70 after three months of treatment. All three groups already after 6 weeks showed improvement, and there was a trend for further improvement in arms 1 and 3, possibly related to discontinuation of bridging therapy with prednisone in arm 2. The effect of prednisone bridging is visible in

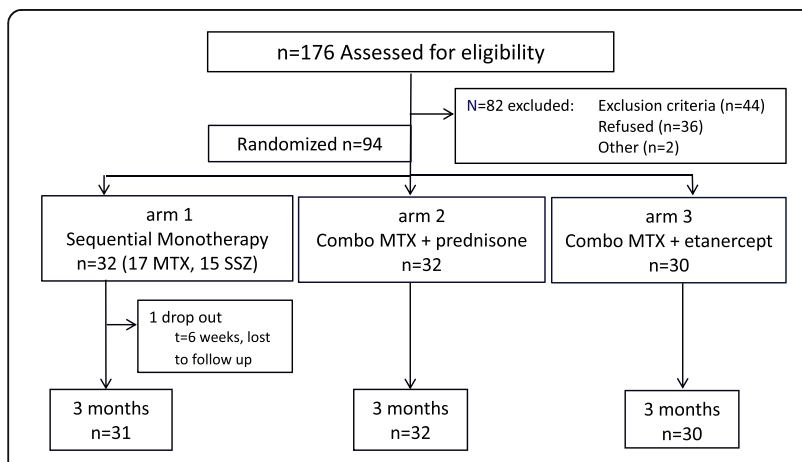

Fig. 1 Study profile of the BeSt for Kids study high aACRPedi 30/50/70\% responses after six weeks but improvements diminished after tapering and stopping of prednisone.

Medication changes had occurred more often in arm 1 and arm 2 as compared to arm 3. Toxicity was comparable and acceptable. A subgroup of arm 1

Table 2 Outcome after 6 weeks and 3 months in BeSt for Kids study

\begin{tabular}{|c|c|c|c|c|}
\hline & $\begin{array}{l}\text { Arm } 1 \\
\text { Sequential } \\
\text { monotherapy } \\
n=32\end{array}$ & $\begin{array}{l}\text { Arm } 2 \\
\text { Combo MTX }+6 \\
\text { wks prednisone } \\
n=32\end{array}$ & $\begin{array}{l}\text { Arm } 3 \\
\text { Combo } \\
\text { MTX+ } \\
\text { etanercept } \\
n=30\end{array}$ & $p$ \\
\hline $\begin{array}{l}\text { Inactive disease } \\
(\%)^{*} 6 w k s \\
3 \text { mths }\end{array}$ & $\begin{array}{l}0(0) \\
8(25)\end{array}$ & $\begin{array}{l}4(13) \\
3(9)\end{array}$ & $\begin{array}{l}1(3) \\
5(17)\end{array}$ & 0.25 \\
\hline $\begin{array}{l}\text { aACR Pedi } 30(\%) 6 \\
\text { wks } \\
3 \text { mths }\end{array}$ & $\begin{array}{l}15(47) \\
16(50)\end{array}$ & $\begin{array}{l}18(56) \\
17(53)\end{array}$ & $\begin{array}{l}17(57) \\
22(73)\end{array}$ & $\begin{array}{l}0.68 \\
0.13\end{array}$ \\
\hline $\begin{array}{l}\text { aACR Pedi } 50(\%) \\
6 w k s \\
3 \text { mths }\end{array}$ & $\begin{array}{l}9(28) \\
10(31)\end{array}$ & $\begin{array}{l}14(44) \\
12(38)\end{array}$ & $\begin{array}{l}11(37) \\
16(53)\end{array}$ & $\begin{array}{l}0.56 \\
0.19\end{array}$ \\
\hline $\begin{array}{l}\text { aACR Pedi } 70(\%) \\
6 w k s \\
3 \text { mths }\end{array}$ & $\begin{array}{l}3(9) \\
8(25)\end{array}$ & $\begin{array}{l}8(25) \\
6(19)\end{array}$ & $\begin{array}{l}6(20) \\
14(47)\end{array}$ & $\begin{array}{l}0.25 \\
0.04\end{array}$ \\
\hline $\begin{array}{l}\text { JADAS-10 (median) } \\
6 w k s \\
3 \text { mths } \\
\triangle \text { JADAS-10 } \\
\text { (median) 6wks } \\
3 \text { mths }\end{array}$ & $\begin{array}{l}13.9 \\
9.0 \\
3.2 \\
6.9\end{array}$ & $\begin{array}{l}9.6 \\
11.5 \\
6.6 \\
5.7\end{array}$ & $\begin{array}{l}12.4 \\
8.2 \\
5.0 \\
10.2\end{array}$ & $\begin{array}{l}0.12 \\
0.25 \\
0.012 \\
0.22\end{array}$ \\
\hline
\end{tabular}


Table 3 Medication changes and protocol violations in first 3 months

\begin{tabular}{|c|c|c|c|}
\hline & $\begin{array}{l}\text { Arm } 1 \\
\text { MTX or SSZ } \\
\text { monotherapy } \\
n=32\end{array}$ & $\begin{array}{l}\text { Arm } 2 \\
\text { Combo } \\
\text { MTX+ } \\
6 \text { wks } \\
\text { prednisone } \\
n=32\end{array}$ & $\begin{array}{l}\text { Arm } 3 \\
\text { Combo } \\
\text { MTX+ } \\
\text { etanercept } \\
n=30\end{array}$ \\
\hline $\begin{array}{l}\text { MTX dose reduction/switch to } \\
\text { SC }\end{array}$ & 2 & 1 & 2 \\
\hline Switch SSZ to MTX & $3 / 15$ & NA & NA \\
\hline $\begin{array}{l}\text { Corticosteroids outside of } \\
\text { protocol } \\
\text {-kenacort intramuscular } \\
\text {-prednisone orally 4-6wk }\end{array}$ & $\begin{array}{l}3 \\
2 \\
1\end{array}$ & $\begin{array}{l}0 \\
0 \\
0\end{array}$ & $\begin{array}{l}0 \\
0 \\
0\end{array}$ \\
\hline $\begin{array}{l}\text { Intra articular corticosteroid } \\
\text { injections }\end{array}$ & 0 & 0 & 0 \\
\hline
\end{tabular}

SSZ sulphasalazine, MTX methotrexate, sc subcutaneous, IM intramuscular, NA not applicable

patients performed better than expected by reaching inactive disease after only three months of monotherapy: 4 of them on SSZ and 4 on MTX (25\% of all patients in arm 1). Inactive disease after 3 months was rare in arm 2 (9\%), and occurred in $17 \%$ of patients in arm 3. Outside-of-protocol use of corticosteroids in arm 1 occurred three times in the first three months, these patients did not reach an ACRPedi50 or inactive disease after three months. Apparently for today's physicians it was hard to hold on to the protocol dictating no additional use of steroids in the current era of impatient doctors and demanding patients, but in this study it helped little to achieve inactive disease.

To minimize the risk of bias of the open design, all outcome measurements were assessed by trained research nurses/physiotherapists/physicians who were blinded to the allocated treatment strategy during entire study period.

Limitations of our study are the relatively small sample size because of slow inclusion rate. These results are promising, but follow up is too short to advocate as yet a primary start with etanercept in DMARD naive new onset JIA patients. The BeSt for Kids study will continue with a treat-to-target design, with medication adjustments aiming to achieve and maintain inactive disease, including after tapering strategies in all three arms. Prospective data on follow-up to 24 months in the BeSt for Kids study will include assessment of possible radiographic joint damage and level of physical functioning.

In conclusion, during the first 3 months of the BeSt for Kids study patients with newly diagnosed JIA who received initial combination therapy with methotrexate and etanercept had significantly more aACRpedi70\% responses, comparable side effects and fewer
Table 4 Toxicity in the three treatment arms

\begin{tabular}{|c|c|c|c|}
\hline Treatment arm & $\begin{array}{l}\text { Arm } 1 \\
\text { Sequential } \\
\text { monotherapy } \\
\text { MTX or SSZ } \\
n=32\end{array}$ & $\begin{array}{l}\text { Arm } 2 \\
\text { Combo MTX }+6 \\
\text { wks prednisone } \\
n=32\end{array}$ & $\begin{array}{l}\text { Arm } 3 \\
\text { Combo } \\
\text { MTX }+ \\
\text { etanercept } \\
n=30\end{array}$ \\
\hline Total number of AEs & 33 & 46 & 39 \\
\hline Number of SAEs & 2 & 1 & 0 \\
\hline Cardiovascular & 0 & 0 & 1 \\
\hline Pulmonary & 1 & 2 & 0 \\
\hline Gastrointestinal & 7 & 14 & 9 \\
\hline -Nausea & 3 & 8 & 6 \\
\hline -Vomiting & 0 & 3 & 1 \\
\hline -Diarrhoea & 0 & 1 & 1 \\
\hline -Rectal Blood loss & 1 & 0 & 0 \\
\hline $\begin{array}{l}\text {-Liver enzyme } \\
\text { abnormality }\end{array}$ & 3 & 2 & 2 \\
\hline Neurologic & 4 & 3 & 2 \\
\hline -Headache & 2 & 0 & 1 \\
\hline -Sleeping disturbances & 1 & 2 & 0 \\
\hline -Behavioral problems & 1 & 1 & 1 \\
\hline Leukopenia & 5 & 1 & 1 \\
\hline Skin/mucosal membranes & 3 & 4 & 3 \\
\hline Infectious & 8 & 6 & 13 \\
\hline $\begin{array}{l}\text {-Upper respiratory tract } \\
\text { infection }\end{array}$ & 1 & 1 & 8 \\
\hline -Gastro-enteritis & 0 & 1 & 1 \\
\hline -Skin/mucosal infection & 1 & 1 & 2 \\
\hline -Fever & 2 & 1 & 1 \\
\hline -Infectious other & 1 & 2 & 1 \\
\hline General malaise/fatigue & 3 & 5 & 1 \\
\hline Other & 0 & 3 & 2 \\
\hline
\end{tabular}

medication changes as compared to methotrexate or sulfasalazine alone or methotrexate and 6 weeks prednisone bridging therapy. Long term follow up data on the extension of initial treatments aiming at inactive disease by a treat to target regime, are needed to relate to these initial positive results.

\section{Abbreviations}

AE: Adverse event; Combo: combination therapy; DMARD: Disease modifying antirheumatic drug; ERA: Enthesitis Related Arthritis; IM: intramuscular; IQR: interquartile Range; JIA: Juvenile idiopathic arthritis; MTX: methotrexate; NSAID: non-steroidal anti-inflammatory drugs; SAE: Serious Adverse event; SC: subcutaneous; SO-JIA: Systemic Onset JIA; SSZ: Sulphasalazine

\section{Acknowledgements}

We would like to thank all participating patients and parents as well as the following physiotherapists and research nurses; Ingrid Honkoop AMC, Annette Hummelman-van Dijk SKZ. Susan Moors physiotherapist SKZ, Jacqueline Bouts, LUMC, Piroska de Boer, LUMC, Veronique van de Lugt, ARC Reade, Stefan Böhringer for statistical help and drs $C$ appels, rheumatologist. 


\section{Funding}

This is an investigator-initiated study which received financial support from Pfizer, who had no role in study design, data collection, data analysis, data interpretation, writing of an abstract, or decision to submit a manuscript for submission.

\section{Availability of data and materials}

The datasets used and/or analysed during the current study available from the corresponding author on reasonable request.

\section{Authors' contributions}

All authors were involved in drafting the article or revising it critically for important intellectual content. All authors approved the final version to be published. Drs HM had full access to all data in the study and takes responsibility for the integrity of the data and the accuracy of the data analysis. Study conception and design: DMCB, CFA, R tenC, LWA van S-S, MAJ van R. Acquisition of data: HM, DMCB, DS, YK-K, JM van den B, TWK, ICJB, DMCB, MAJ van $R$, LWA vanS-S, CFA, R tenC. Analysis and interpretation of data: HM, DMCB, LWA van S-S, CFA, R tenC. Critically revising the manuscript; DMCB, DS, YK-K, IB, WPB, TWK, MAJ van $R$, LWA van S-S, JM van den $B$, CFA, $R$ tenC.

\section{Competing interests}

The authors declare that they have no competing interests.

\section{Consent for publication}

Not applicable.

\section{Ethics approval and consent to participate}

Approval of the Medical Ethical Committee of the Leiden University Medical Center and local Ethical Committees was obtained prior to start at each study site. Written Informed consent was obtained from patients above 12 years of age and parents of all participating patients.The authors declare that they have no competing interests.

\section{Author details}

${ }^{1}$ Department of Pediatrics/Pediatric Rheumatology, Leiden University Medical Center, Leiden, The Netherlands. '2Department of Pediatrics, Alrijne Hospital Leiderdorp, Leiderdorp, The Netherlands. ${ }^{3}$ Department of Pediatric Hematology, Immunology, Rheumatology and Infectious Diseases, Emma Children's Hospital AMC, University of Amsterdam, Amsterdam, The Netherlands. ${ }^{4}$ Department of Pediatrics, Hagaziekenhuis Juliana Children's Hospital, The Hague, The Netherlands. ${ }^{5}$ Department of Pediatric Rheumatology, Amsterdam Rheumatology and Immunology Center location Reade Amsterdam, Amsterdam, The Netherlands. 'Department of Pediatrics/ Pediatric Rheumatology, Erasmus MC Sophia Children's Hospital, Rotterdam, The Netherlands. ${ }^{7}$ Department of Rheumatology, Leiden University Medical Center, Leiden, The Netherlands.

Received: 11 November 2016 Accepted: 19 January 2017

Published online: 06 February 2017

\section{References}

1. Prakken B, Albani S, Martini A. Juvenile idiopathic arthritis. Lancet. 2011; 377(9783):2138-49.

2. Vastert SJ, Kuis W, Grom AA. Systemic JIA: new developments in the understanding of the pathophysiology and therapy. Best Pract Res Clin Rheumatol. 2009;23(5):655-64.

3. Selvaag AM, Aulie HA, Lilleby $V$, Flato B. Disease progression into adulthood and predictors of long-term active disease in juvenile idiopathic arthritis. Ann Rheum Dis. 2014.

4. Petty RE, Southwood TR, Baum J, Bhettay E, Glass DN, Manners P, Maldonado-Cocco J, Suarez-Almazor M, Orozco-Alcala J, Prieur AM. Revision of the proposed classification criteria for juvenile idiopathic arthritis: Durban, 1997. J Rheumatol. 1998;25(10):1991-4.

5. Albers HM, Brinkman DM, Kamphuis SS, van Suijlekom-Smit LW, van Rossum MA, Hoppenreijs EP, Girschick HJ, Wouters C, Saurenmann RK, HouwingDuistermaat JJ, et al. Clinical course and prognostic value of disease activity in the first two years in different subtypes of juvenile idiopathic arthritis. Arthritis Care Res (Hoboken ). 2010;62(2):204-12.

6. Hinze C, Gohar F, Foell D. Management of juvenile idiopathic arthritis: hitting the target. Nat Rev Rheumatol. 2015.
7. Wallace CA. The use of methotrexate in childhood rheumatic diseases. Arthritis Rheum. 1998;41(3):381-91.

8. Lovell DJ, Giannini EH, Reiff A, Cawkwell GD, Silverman ED, Nocton JJ, Stein LD, Gedalia A, llowite NT, Wallace CA, et al. Etanercept in children with polyarticular juvenile rheumatoid arthritis. Pediatric Rheumatology Collaborative Study Group. N Engl J Med. 2000;342(11):763-9.

9. Lovell DJ, Reiff A, llowite NT, Wallace CA, Chon Y, Lin SL, Baumgartner SW, Giannini EH. Safety and efficacy of up to eight years of continuous etanercept therapy in patients with juvenile rheumatoid arthritis. Arthritis Rheum. 2008;58(5):1496-504.

10. Giannini EH, llowite NT, Lovell DJ, Wallace CA, Rabinovich CE, Reiff A, Higgins G, Gottlieb B, Singer NG, Chon Y, et al. Long-term safety and effectiveness of etanercept in children with selected categories of juvenile idiopathic arthritis. Arthritis Rheum. 2009;60(9):2794-804.

11. van Rossum MA, van Soesbergen RM, Boers $M$, Zwinderman $A H$, Fiselier $T$ J, Franssen MJ, ten CR, van Suijlekom-Smit LW, Wulffraat NM, van Luijk WH, et al. Long-term outcome of juvenile idiopathic arthritis following a placebo-controlled trial: sustained benefits of early sulfasalazine treatment. Ann Rheum Dis. 2007;66(11):1518-24.

12. Klein A, Kaul I, Foeldvari I, Ganser G, Urban A, Horneff G. Efficacy and safety of oral and parenteral methotrexate therapy in children with juvenile idiopathic arthritis: an observational study with patients from the German Methotrexate Registry. Arthritis Care Res (Hoboken). 2012;64(9):1349-56.

13. Giannini EH, Brewer EJ, Kuzmina N, Shaikov A, Maximov A, Vorontsov I, Fink CW, Newman AJ, Cassidy JT, Zemel LS. Methotrexate in resistant juvenile rheumatoid arthritis. Results of the U.S.A.-U.S.S.R. double-blind, placebocontrolled trial. The Pediatric Rheumatology Collaborative Study Group and The Cooperative Children's Study Group. N Engl J Med. 1992;326(16):1043-9.

14. Giannini EH, Cassidy JT, Brewer EJ, Shaikov A, Maximov A, Kuzmina N. Comparative efficacy and safety of advanced drug therapy in children with juvenile rheumatoid arthritis. Semin Arthritis Rheum. 1993;23(1):34-46.

15. Woo P, Southwood TR, Prieur AM, Dore CJ, Grainger J, David J, Ryder C, Hasson N, Hall A, Lemelle I. Randomized, placebo-controlled, crossover trial of low-dose oral methotrexate in children with extended oligoarticular or systemic arthritis. Arthritis Rheum. 2000;43(8):1849-57.

16. Tynjala $P$, Vahasalo $P$, Tarkiainen $M$, Kroger L, Aalto K, Malin M, Putto-Laurila A, Honkanen V, Lahdenne P. Aggressive combination drug therapy in very early polyarticular juvenile idiopathic arthritis (ACUTE-JIA): a multicentre randomised open-label clinical trial 264 Ann Rheum Dis. 2011;70(9):1605-12.

17. Wallace CA, Giannini EH, Spalding SJ, Hashkes PJ, O'Neil KM, Zeft AS, Szer IS, Ringold S, Brunner HI, Schanberg LE, et al. Trial of early aggressive therapy in polyarticular juvenile idiopathic arthritis. Arthritis Rheum. 2011;64(6):2012-21.

18. Goekoop-Ruiterman YP, de Vries-Bouwstra JK, Allaart CF, Van ZD, Kerstens PJ, Hazes JM, Zwinderman AH, Peeters AJ, de Jonge-Bok JM, Mallee C, et al. Comparison of treatment strategies in early rheumatoid arthritis: a randomized trial. Ann Intern Med. 2007;146(6):406-15.

19. Albers HM, Wessels JA, van der Straaten RJ, Brinkman DM, Suijlekom-Smit LW, Kamphuis SS, Girschick HJ, Wouters C, Schilham MW, le CS, et al. Time to treatment as an important factor for the response to methotrexate in juvenile idiopathic arthritis. Arthritis Rheum. 2009;61(1):46-51.

20. Bartoli M, Taro M, Magni-Manzoni S, Pistorio A, Traverso F, Viola S, Magnani A, Gasparini C, Martini A, Ravelli A. The magnitude of early response to methotrexate therapy predicts long-term outcome of patients with juvenile idiopathic arthritis. Ann Rheum Dis. 2008;67(3):370-4.

21. Oen K, Duffy CM, Tse SM, Ramsey S, Ellsworth J, Chedeville G, Chetaille AL, Saint-Cyr C, Cabral DA, Spiegel LR, et al. Early outcomes and improvement of patients with juvenile idiopathic arthritis enrolled in a Canadian multicenter inception cohort. Arthritis Care Res (Hoboken ). 2010;62(4):527-36.

22. Schmeling $H$, Horneff $G$. Etanercept and uveitis in patients with juvenile idiopathic arthritis. Rheumatology (Oxford). 2005:44(8):1008-11.

23. Saurenmann RK, Levin AV, Feldman BM, Laxer RM, Schneider R, Silverman ED. Risk of new-onset uveitis in patients with juvenile idiopathic arthritis treated with anti-TNFalpha agents. J Pediatr. 2006;149(6):833-6.

24. Anink J, Otten MH, Gorter SL, Prince FH, van Rossum MA, van den Berg JM, van Pelt PA, Kamphuis S, Brinkman DM, Swen WA, et al. Treatment choices of paediatric rheumatologists for juvenile idiopathic arthritis: etanercept or adalimumab? Rheumatology (Oxford). 2013;52(9):1674-9. 
25. Tynjala P, Lindahl P, Honkanen V, Lahdenne P, Kotaniemi K. Infliximab and etanercept in the treatment of chronic uveitis associated with refractory juvenile idiopathic arthritis. Ann Rheum Dis. 2007;66(4):548-50.

26. Wendling D, Paccou J, Berthelot JM, Flipo RM, Guillaume-Czitrom S, Prati C, Dernis E, Direz G, Ferrazzi V, Ristori JM. New onset of uveitis during antitumor necrosis factor treatment for rheumatic diseases. Semin Arthritis Rheum. 2011;41(3):503-10

27. Giannini EH, Ruperto N, Ravelli A, Lovell DJ, Felson DT, Martini A. Preliminary definition of improvement in juvenile arthritis 14. Arthritis Rheum. 1997;40(7):1202-9.

28. Wallace CA, Ruperto N, Giannini E. Preliminary criteria for clinical remission for select categories of juvenile idiopathic arthritis. J Rheumatol. 2004;31(11): 2290-4.

29. Wallace CA, Giannini EH, Huang B, Itert L, Ruperto N. American College of Rheumatology provisional criteria for defining clinical inactive disease in select categories of juvenile idiopathic arthritis. Arthritis Care Res (Hoboken ). 2011:63(7):929-36.

30. Prince FH, Twilt $M$, ten $C R$, van Rossum MA, Armbrust W, Hoppenreijs EP, van Santen-Hoeufft M, Koopman-Keemink Y, Wulffraat NM, van SuijlekomSmit LW. Long-term follow-up on effectiveness and safety of etanercept in juvenile idiopathic arthritis: the Dutch national register. Ann Rheum Dis. 2009:68(5):635-41.

31. Consolaro A, Ruperto N, Bazso A, Pistorio A, Magni-Manzoni S, Filocamo G, Malattia C, Viola S, Martini A, Ravelli A. Development and validation of a composite disease activity score for juvenile idiopathic arthritis. Arthritis Rheum. 2009;61(5):658-66.

\section{Submit your next manuscript to BioMed Central} and we will help you at every step:

- We accept pre-submission inquiries

- Our selector tool helps you to find the most relevant journal

- We provide round the clock customer support

- Convenient online submission

- Thorough peer review

- Inclusion in PubMed and all major indexing services

- Maximum visibility for your research

Submit your manuscript at www.biomedcentral.com/submit 